\title{
Al-powered Motion Interaction for 3D Cultural Heritage
}

Abdelhak Belhi, CSE, College of Engineering, Qatar University Project Supervisor: Prof. Abdelaziz Bouras
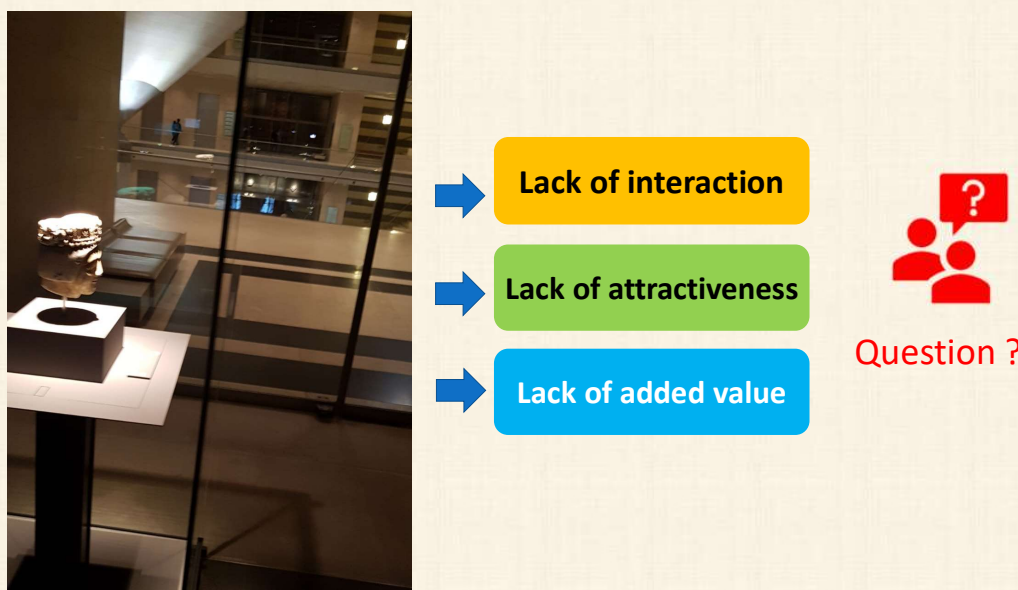

Question ???

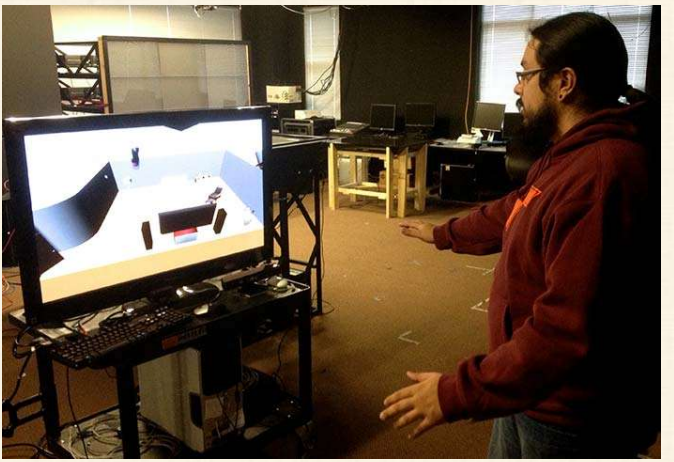

How to cost effectively achieve end user immersion with consumer level hardware

A museum object in a glass box in a reasonable amount of time?
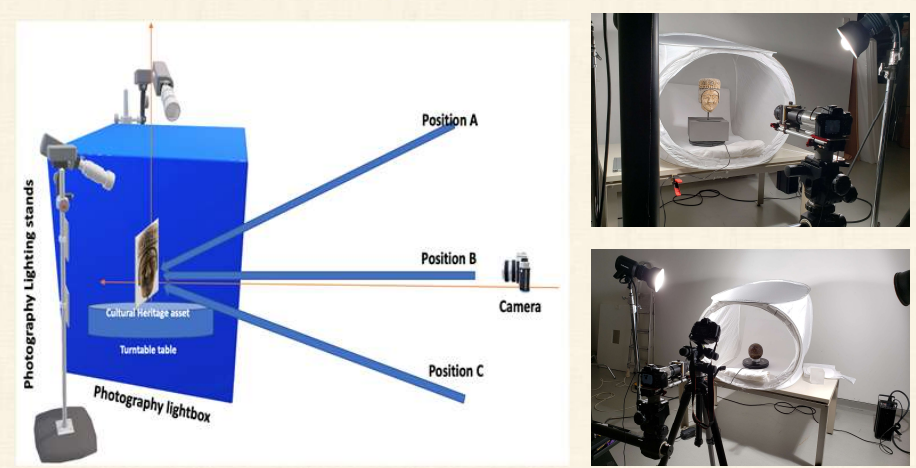

Step 1: 3D acquisition setup with consumer level hardware
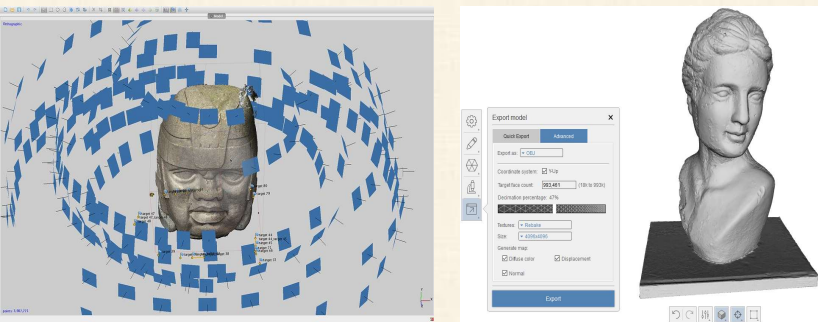

Step 3: 3D modelling using advanced photogrammetry

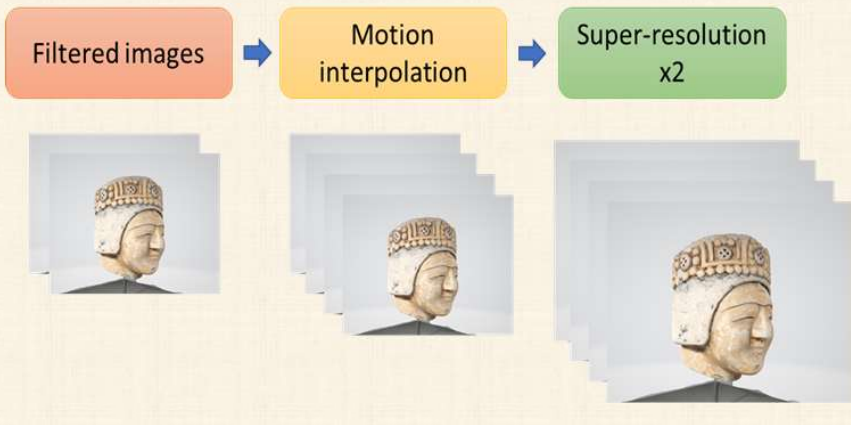

Step 2: In-between frame interpolation and super resolution
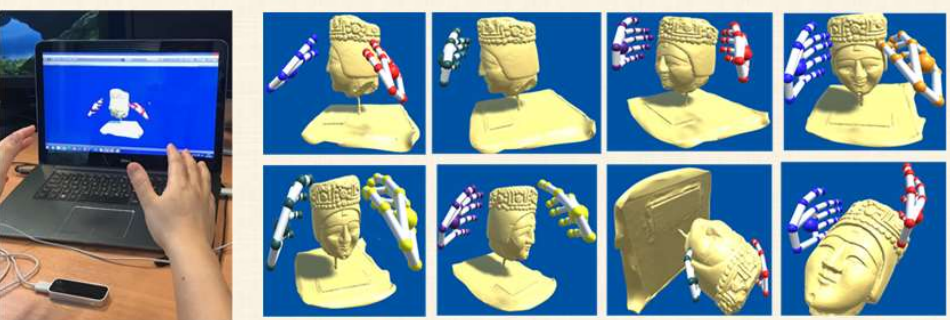

Step 4: Interaction using hands with the leap motion controller

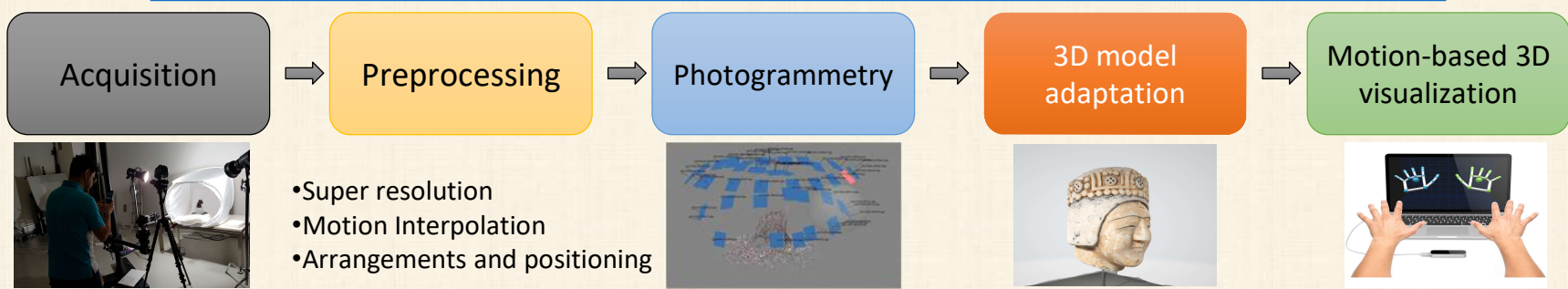

Framework architecture

\section{References}

[1] Gomes, L., Bellon, O.R.P., Silva, L.: 3D reconstruction methods for digital preservation of cultural heritage: A survey. Pattern Recognition Letters 50, 3-14 (2014)

[2] Gonizzi Barsanti, S,: 3D visualization of cultural heritage artefacts with virtual reality devices. In: 25th International CIPA Symposium 2015, pp. 165-172. Copernicus Gesellschaft mbH, (2015)

[3] Manresa, C.: Hand tracking and gesture recognition for human-computer interaction. ELCVIA Electronic Letters on Computer Vision and Image Analysis 5, 96-104 (2005)

[4] Weichert, F.: Analysis of the accuracy and robustness of the leap motion controller. Sensors 13, 6380-6393 (2013)

\section{Acknowledgment}

This publication was made possible by NPRP grant 9-181-1-036 from the Qatar National Research Fund (a member of Qatar Foundation). This work was also supported by Qatar Museums and the Museum of Islamic Art (Doha, Qatar). The statements made herein are solely the responsibility of the authors (www.ceproqha.qa).

\section{Contact}

Abdelhak Belhi

Organization/Affiliation: CSE, College of Engineering, Qatar University
Email: abdelhak.belhi@qu.edu.qa

Website: www.ceproqha.qa Phone: +974 33088382 